\title{
Efficacy of Probiotic Saccharomyces boulardii as an Adjuvant Therapy in Acute Childhood Diarrhoea
}

\author{
Dash DK ${ }^{1}$, Dash $\mathbf{M}^{2}$, Mohanty MD³ ${ }^{3}$ Acharya ${ }^{4}$
}

${ }^{1}$ Dr. Dillip Kumar Dash MBBS, MD, Professor, ${ }^{2}$ Dr. Mrutunjaya Dash MBBS, MD, Professor, ${ }^{3} \mathrm{Dr}$ M.D. Mohanty MBBS, MD, Professor, ${ }^{4} \mathrm{Dr}$ Naresh Acarya, MBBS, MD. Senior Resident. All from the Department of Paaediatrics, IMS and SUM Hospital, Bhubaneswar.

\section{Address for correspondence: \\ Dr. Dillip Kumar Dash, Associate Professor Department of Paediatrics, \\ IMS and SUM Hospital, Kalinga Nagar, Bhubaneswar, Odissa, India \\ Tel: +919437167337 \\ E-mail: drdillipdash10.10@gmail.com}

Acknowledgements: The authors are thankful to Central Research Laboratory, IMS and SUM Hospital for the help for drafting of the manuscript.

Funding: Nil

Conflict of Interest: None

Permission from IRB: Yes

Ethical dilemmas faced during study: No

\section{How to cite}

Dash DK, Dash M, Mohanty MD, Acharya N. Efficacy of Probiotic Saccharomyces boulardii as an Adjuvant Therapy in Acute Childhood Diarrhoea. J Nepal Paediatr Soc 2016;36(3):250-255.

doi: http://dx.doi.org/10.3126/jnps.v36i3.15539

This work is licensed under a Creative Commons Attribution 3.0 License.

\begin{abstract}
Introduction: Administration of $S$. boulardii in addition to rehydration therapy in diarrhea found to be beneficial in many aspects owing to a variety of causes and importantly it is was not associated with any adverse effects. Material and Methods: We conducted a prospective study of children suffering from acute diarrhoea, at a private tertiary care hospital. Children were divided into 2 groups randomly as per odd(Group 1 ) and even (Group 2) bed allotted in indoor at the time of admission: Group 1 included children on oral rehydration therapy (ORT) + Zinc + Saccharomyces boulardii(Probiotic 5 billion CFU twice daily) and Group 2 comprised of children on ORT+ Zinc. Our objective was to systematically review data on the effect of $S$. boulardii on acute childhood diarrhoea.Results:Out of a total of 126 children less than 2 years, 2-6 years and 6-14 years were $72(57.14 \%), 42(33.33 \%)$ and $12(09.52 \%)$ respectively. The duration of diarrhoea in Group 1 was 26.31 hours and Group 2 was 47.81 hours $(p<0.01)$. The frequency of diarrhoea showed improvement within 24 and 72 hours in Group 1 and Group 2 respectively $(p<0.01)$.Similarly, the mean duration of hospital stay was 2.68 days in Group 1 and 4.8 days in Group 2.The treatment cost was INR 850 and INR 1650 while social cost was INR 1250 and 2600 in Group 1 and 2 respectively. Conclusion:This study shows that $S$. boulardii reduced the duration, frequency and hospital stay of diarrhoea thereby reducing the treatment and social costs.
\end{abstract}

Key words: Childhood diarrhoea, Saccharomyces boulardii, therapy.

\section{Introduction}

$\mathrm{D}$ arrhea is defined by the World Health Organization (WHO) as 3 or more passage of loose or watery stool and increments in stool frequency in a 24-hour period. Diarrhoea with any cause and any period of time may lead to dehydration and even may be lethal in infants, children, and the elderly if not corrected immediately 1. Bacterio-therapy is known to play an important role in intestinal dysbiosis and judicious use of probiotics could reduce the duration and frequency of diarrhoea ${ }^{2,3}$ The most common cause of diarrhoea is a gut infection (viral, bacterial, and parasitic). Other causes include 
adverse effects of medicine (especially antibiotics), infections not associated with the gastrointestinal tract, food poisoning, and allergy ${ }^{4}$.Diarrhoea is also categorized into acute (lasts several hours or days) and persistent (continues for 14 days or longer). Globally, $\sim 1.7$ billion cases of diarrheal disease occur every year, resulting in nearly 760000 deaths in children younger than age five years, especially in developing countries $^{5}$. In many clinical trials, S. boulardii has been shown to be effective in prevention and management of diarrhea, especially antibiotic-associated diarrhea. $S$. boulardii can be administered simultaneously to prevent antibiotic-associated diarrhea owing to its resistance to most antibiotics ${ }^{6}$. The Cochrane review of meta-analysis has shown a decrease in duration and frequency of acute diarrhoea within 24 hours ${ }^{6,7}$ The efficacy of S. boulardii has been documented in various types of diarrhea such as the prevention of antibiotic-associated diarrhea ${ }^{8}$.

Aims and Objectives: To evaluate the role of $S$. boulardii related to: Duration of diarrhoea, frequency of diarrhoea, complications, hospital stay the direct and indirect costs involved.

\section{Material and Methods}

We studied 126 children admitted to the paediatric ward of a private tertiary care hospital. Cases were divided into two groups: Group 1 comprised of children who were administered oral rehydration therapy (ORT) with Zinc and $S$. boulardii(5 billion CFU in each sachet twice daily) and Group 2 was treated with ORT and Zinc.ORS and diet was given to both groups with no difference. It was a prospective, randomized, open label, comparative study. Data was filled in a pre-designed preform and statistical analysis was done using the Chi square test and sample t test of proportion.

Children were administered 5 billion sachetS. boulardii12 hourly for 5 days. They were followed up at 6 hours, 12 hours, 24, 36, 48, 60 and 72 hours.

Institutional Ethics Committee approval was taken and an informed consent with assent was obtained before enrolling the subjects in the study.
Inclusion Criteria included; Age between 6 months to 14 years, children with mild to moderate dehydration and no prior probiotic administration.

Exclusion Criteria included;Age $<6$ months, cases with chronic and severe diarrhoea, children transferred to PICU and parents refusal to participate in the study.

Safety was evaluated by assessing the incidence and type of adverse effects such as increase in blood pressure, Electrolyte imbalance and pulse rate, physical examination and clinical laboratory tests, i.e. complete blood count, serum creatinine, and stool examination both microscopy and routine, on day 1 and day 3 .

\section{Results}

We studied 126 cases of which Group 1 and Group 2 comprised of 64 cases and 62 cases respectively of whom $88(63.4 \%)$ were males and $38(36.6 \%)$ were females Table1. Children less than 2 years were 72 (57.14\%); 2-6 years were 42 (33.33\%) and 6-14 years were $12(9.52 \%)$ Table1.The duration of diarrhoea in Group 1 was 26.31 hours and Group 2 was 48.71 hours $(p<0.01)$ Fig-1. The frequency of stool in Group 1 and Group 2 reduced within 24 and 60 hours respectively $(p<0.01)$ Fig-2.The mean duration of hospital stay was 2.68 days when compared to 4.8 days in Group 1 and 2 (Fig 4). The cost of treatment was INR 850 in Group 1 and INR 1680 in Group 2 (Fig 3). The indirect and social cost was INR1250 and INR 2600 in the above groups respectively (Fig5).Cost of each sachet of $S$. boulardii was rupees 35 INR and was purchased by parents from pharmacy.

Table 1: Age and sex distribution of 126 patients in the study

\begin{tabular}{ccccc}
\hline \multirow{2}{*}{ Age (years) } & \multicolumn{2}{c}{ Sex } & \multirow{2}{*}{ Total } & $\%$ \\
\cline { 2 - 3 } & Males & Females & & \multirow{2}{*}{ \% } \\
\hline < 2 year & 52 & 20 & 72 & 57.14 \\
\hline 2-6 year & 28 & 14 & 42 & 33.33 \\
\hline 6-14 year & 08 & 04 & 12 & 09.52 \\
\hline
\end{tabular}




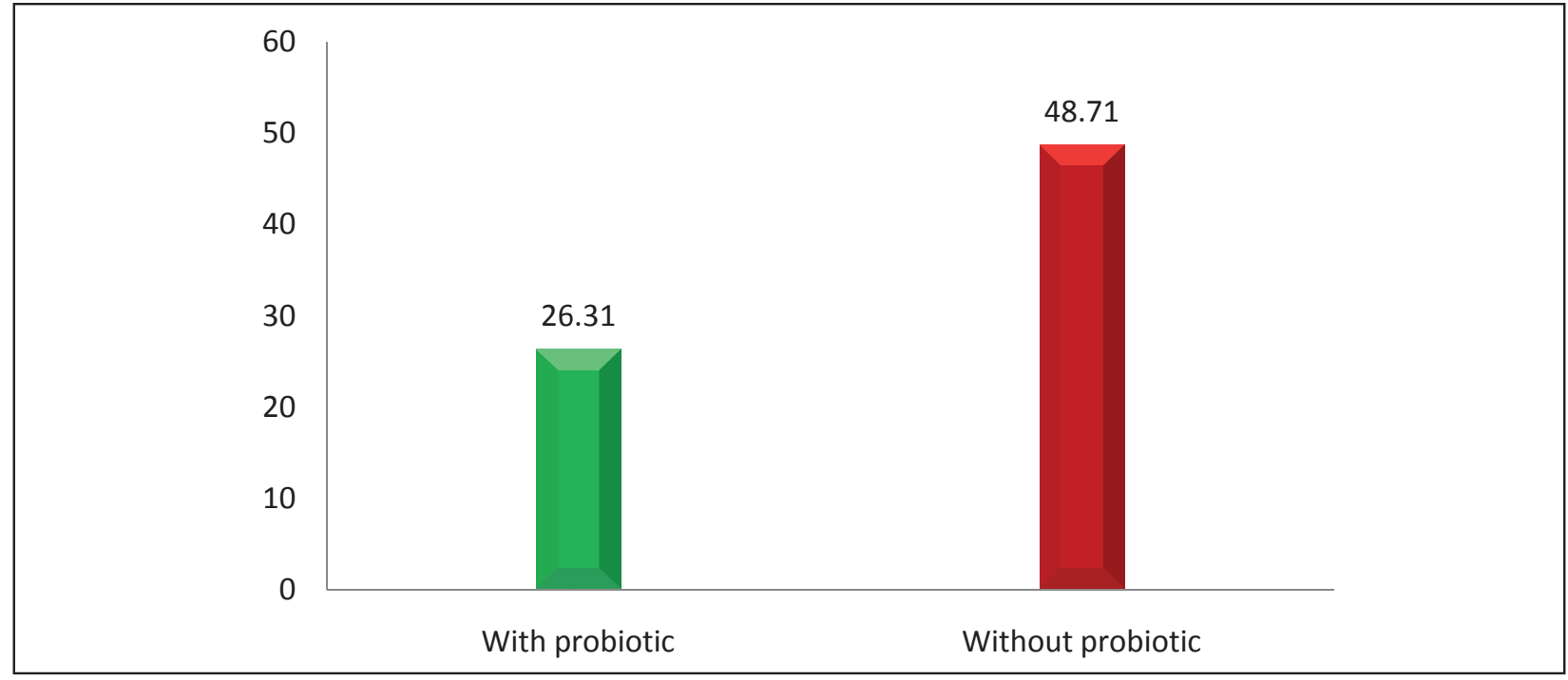

Fig 1: Hours required improving the consistency of stool or duration of diarrhoea

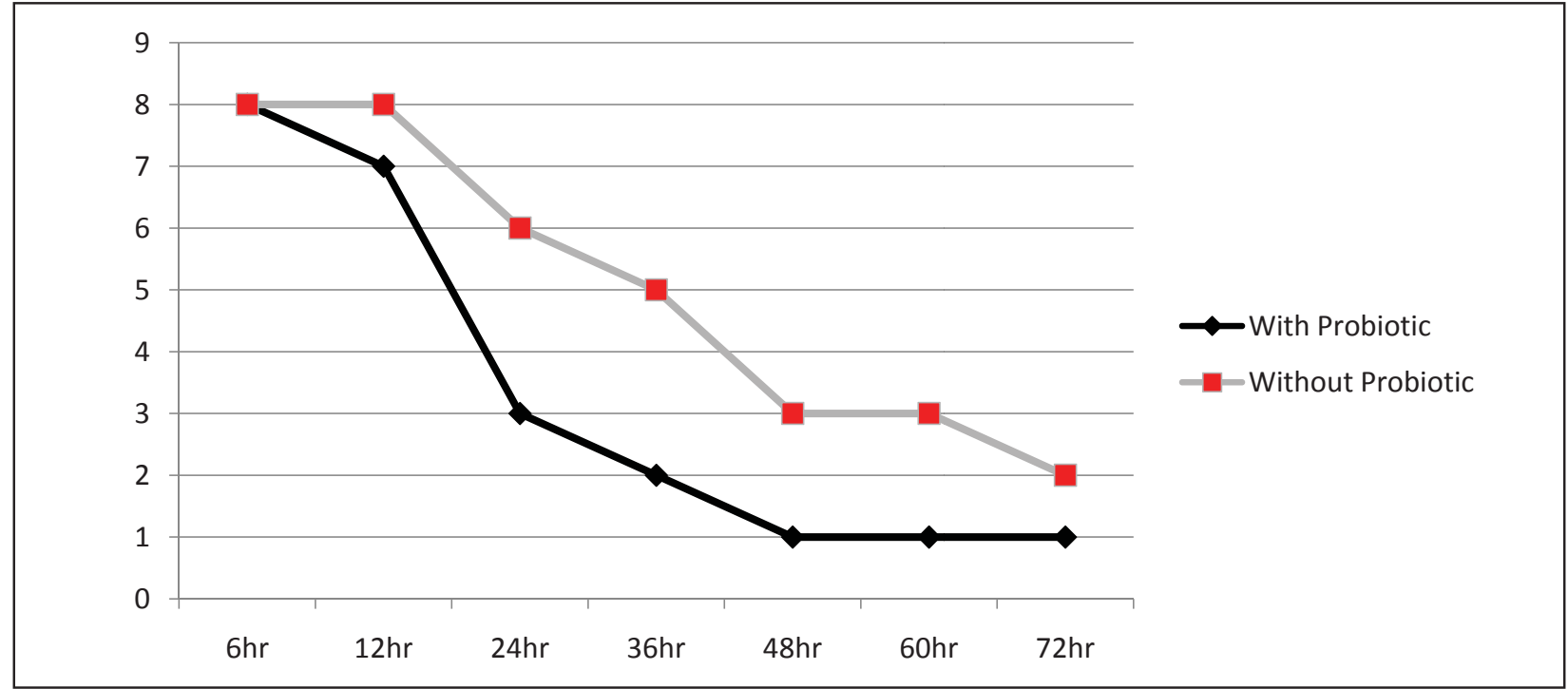

Fig 2: Comparison of frequency of stool in patient with and without probiotics

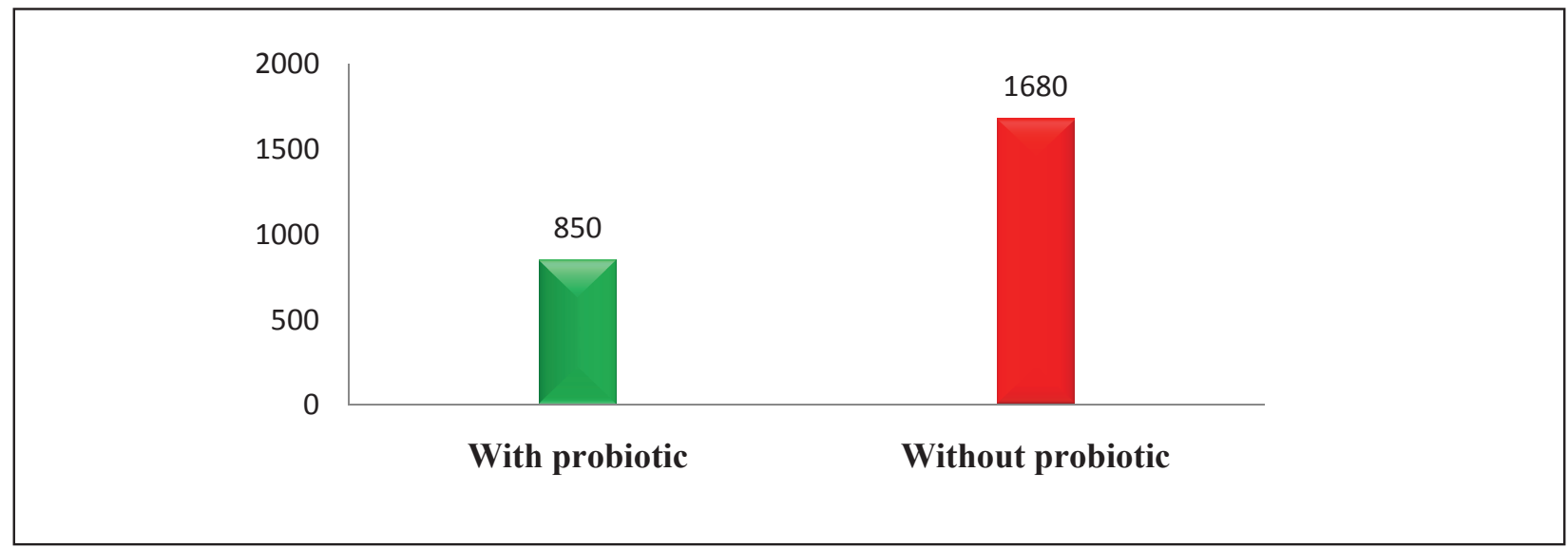

Fig 3: Treatment cost (Rupees) 


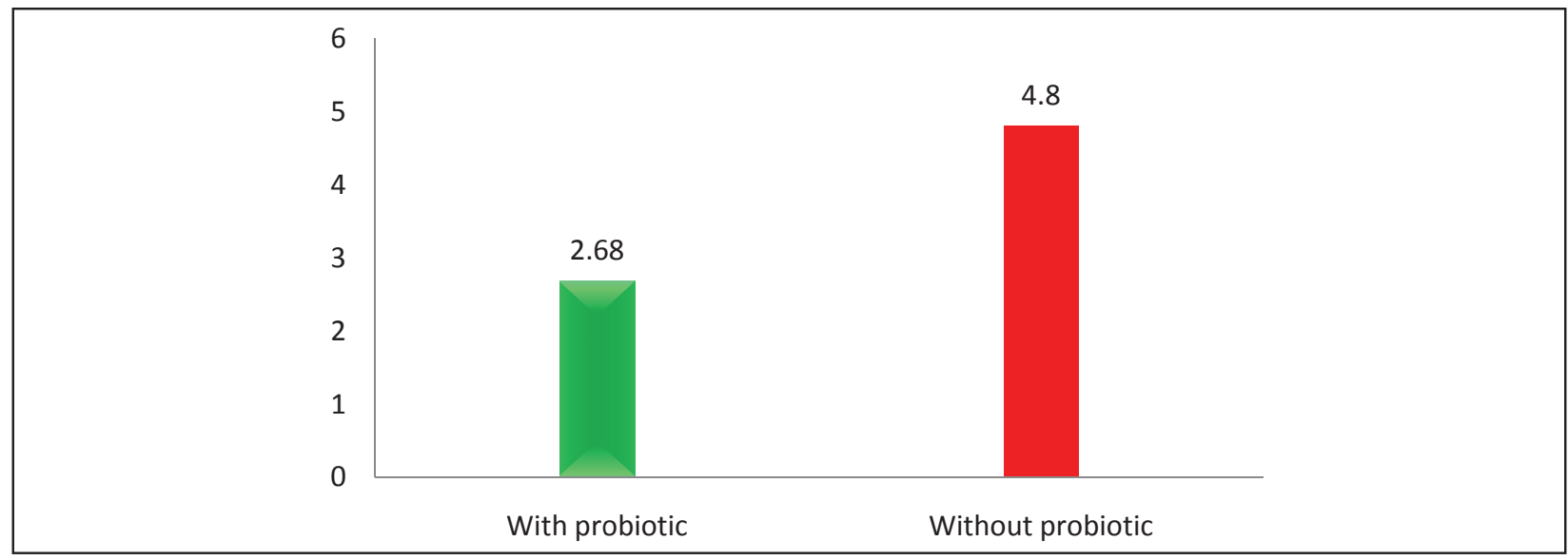

Fig 4: Mean duration of hospital stay

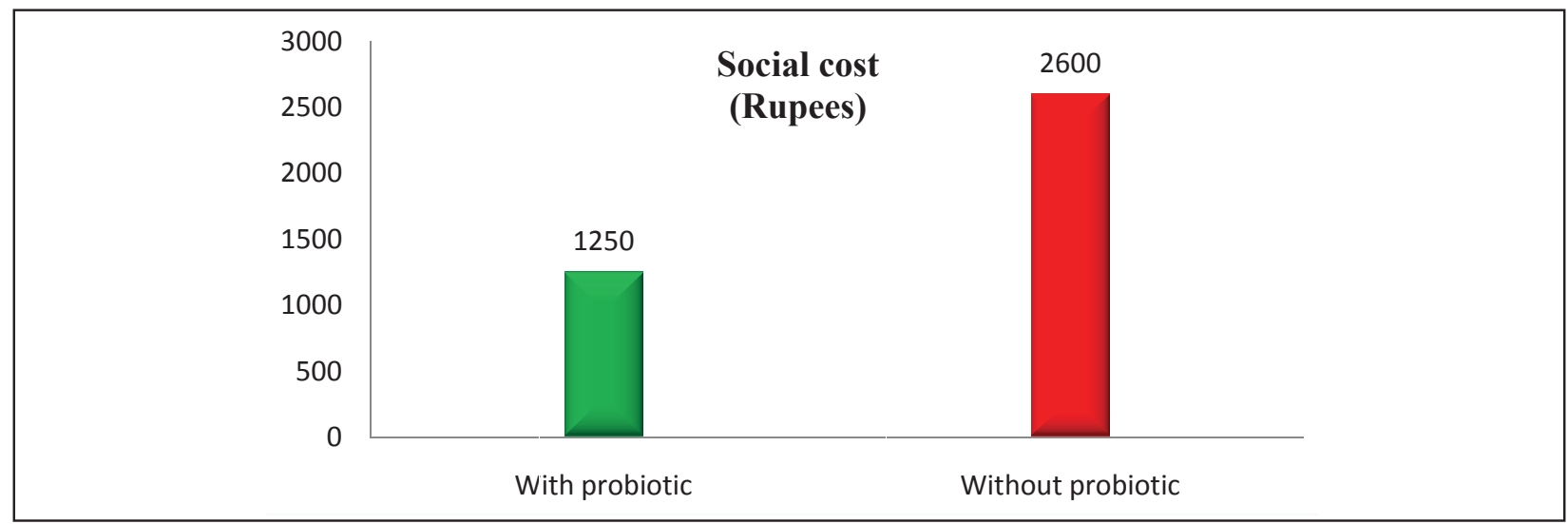

Fig 5: Social Cost

\section{Discussion}

Saccharomyces boulardii is beneficial yeast that was first isolated from lychee and mangosteen fruit. In many clinical trials, $S$. boulardii has been shown to be effective in prevention and management of diarrhea, especially antibiotic-associated diarrhea. S. boulardii can be administered simultaneously to prevent antibiotic-associated diarrhea owing to its resistance to most antibiotics.Clostridium difficileassociated enteropathies ${ }^{9} \mathrm{chronic}$ diarrhea caused by giardiasis ${ }^{10}$ and amebiasis ${ }^{11,12}$, prevention of traveler's diarrhea ${ }^{13,14}$ prevention of diarrhea in critically ill tube-fed patients ${ }^{15}$ and treatment of human immunodeficiency virus-associated diarrhea ${ }^{16}$ However, the major indication is acute diarrhea in children and adults ${ }^{17,18,19}$.An increasing number of potential health benefits are being attributed to probiotic treatments ${ }^{20,21,25,26}$. However, only a limited number have been confirmed in well-designed and conducted randomized controlled trials (RCTs) and even less in the pediatric population. $S$. boulardii is a live yeast used extensively as a probiotic and often marketed as a dietary supplement ${ }^{27}$.Several mechanisms of action have been identified directed against the host as well as pathogenic microorganisms and include regulation of intestinal microbial homeostasis, interference with the ability of pathogens to colonize and infect the mucosa, modulation of local and systemic immune responses, stabilization of the gastrointestinal barrier function and induction of enzymatic activity favoring absorption and nutrition ${ }^{25,26,23,28}$. The normal gut micro biota in acute diarrhea is disrupted in children and in the present study; we have tried to highlight the therapeutic efficacy of $S$. boulardii.The duration of diarrhoea was significantly altered in Group 1; 26.31 hours when compared to Group 2; 48.71 hours $(p<0.001$, t test $=16.014)($ Fig 1) The result of $t$ test revealed that the mean frequency of stool in Group 1 was significantly less as compared to Group $2 \quad(p<0.001)$ and improved within 24-36 hours, (Fig 2) thus preventing fluid loss and electrolyte imbalance. The patients in Group 1 were discharged within 3 to 4 days while Group 2 had a longer stay of 6 to 8 days $(p<0.001)$.S. boulardii has been tested for clinical efficacy in several types of acute gastrointestinal conditions, including antibiotic-associated diarrhoea $(A A D)^{28}$ Clostridium difficile infection (CDI) ${ }^{29}$,acute diarrhoea, enteral nutrition-related diarrhoea, traveller's diarrhoea and Helicobacter pylori infection ${ }^{30,31,32,33}$. $S$. boulardii has been tested for clinical efficacy in several types of chronic diseases including Crohn's disease, 
ulcerative colitis, irritable bowel syndrome (IBS), parasitic infections and human immunodeficiency virus (HIV)-related diarrhea ${ }^{34,35,36,37}$. Interleukin (IL-8) is a proinflammatorycytokine secreted during an $E$. coli infection in the gut. $S$. boulardii has been shown to decrease the secretion of IL-8 during an E. coli infection; $S$. boulardii could have a protective effect in inflammatory bowel disease ${ }^{38}$. The trophic effect on enterocytes has been shown to increase levels of disaccharidases such as lactase, sucrase, maltase, glucoamylase, and $\mathrm{N}$-aminopeptidase in the intestinal mucosa of humans and rats. This can lead to the increased breakdown of disaccharides into monosaccharides that can then be absorbed into the bloodstream via enterocytes ${ }^{38,39}$. This can help in the treatment of diarrhea, as the level of enzymatic activity has diminished and carbohydrate cannot be degraded and absorbed.S. boulardii induces the secretion of immunoglobulin $A$ in the small intestine of the rat ${ }^{38,39}$. Previous reports reveal The cost of treatment was INR 779 in probiotic group (Bacillus

\section{References}

1. NataroJP .Diarrhea among children in developing countries.AdvExp Med Biol. 2013;764:73-80 pmid:23654057 .

2. World Health Organization: The treatment of diarrhoea: a manual for physicians and other senior health workers, Geneva, 1995, World Health Organization;

3. Centers for Disease Control and Prevention. Diagnosis and Management of Foodborne IIInesses: A Primer for Physicians and Other Health Care Professionals. MMWR 2004;53(No. RR-4):[inclusive page numbers].

4. Hill C, Sanders ME. Rethinking "probiotics". Gut Microbes 2013;4:269-70.

5. PawlowskiSW, Warren CA, Guerrant R . Diagnosis and treatment of acute or persistent diarrhea. Gastroenterology 2009;136(6):1874-1886 pmid:19457416.

6. World Health Organization. Medicenter.Diarrhoeal disease. April 2013. Available at: www.who.int/ mediacentre/factsheets/fs330/en/. Accessed September 14, 2013

7. PozzoniP, Riva A, Bellatorre AG, et al. Saccharomyces boulardii for the prevention of antibiotic-associated diarrhea in adult hospitalized patients: a singlecenter, randomized, double-blind, placebo-controlled trial. Am J Gastroenterol 2012;107(6):922-931 pmid:22472744).

8. Allen SJ, Okoko B, Martinez E, Gregorio G,Dans LF. Probiotics for treating infectious diarrhoea. Cochrane Database Systemic Rev2004;(2):CD003048. clausii) and INR 944 in without probiotic group. Similarly the indirect and social cost was INR 937 and INR 1409 in the above groups respectively ${ }^{40}$. In our present study treatment and indirect social cost closely matching the previous study

\section{Conclusions}

Administration of $S$. boulardii in addition to rehydration therapy in diarrhea found to be beneficial in many aspects owing to a variety of causes and importantly it is was not associated with any adverse effects as shown in our present study.

Recommendation: Further clinical studies are needed to identify different causes of diarrhea for each participant, and especially more studies should be performed in children who have bacterial and parasitic diarrhea and efficacy of $S$. boulardii in each group. Limitation of this study was, it was a hospital based study, and needs large population based study to get more convincing results.

9. Surawicz CM, Elmer GW, Speelman P, McFarland LV, Chinn J, van Belle G. Prevention of antibioticassociated diarrhea by Saccharomyces boulardii: a prospective study. Gastroenterology 1989;96:981-88.

10. Buts JP, Corthier G, DelmeeM. Saccharomyces boulardii for Clostridium difficile-associated enteropathies in infants. J PediatrGastroenterolNutr1993;16: 419-25.

11. Besirbellioglu BA, Ulcay A, Can M, Erdem H, Tanyuksel M, Avci IY, Araz E, Pahsa A. Saccharomyces boulardii and infection due to Giardia lamblia.Scand J Infect Dis 2006;38:479-81.

12. Dahan S; Dalmasso G; Imbert V; Peyron JF; Rampal P; Czerucka D. "Saccharomyces boulardii interferes with enterohemorrhagic Escherichia coli-induced signaling pathways in T84 cells". Infect Immun2003;71(2):766-73. doi:10.1128/IAI.71.2.766-773.2003.

13. Mansour-Ghanaei F, Dehbashi N, Yazdanparast K, Shafaghi A, 2003. Efficacy of Saccharomyces boulardii with antibiotics in acute amoebiasis. World $\mathrm{J}$ Gastroentero/2003;9:1832-833.

14. Center for Disease Control and Prevention: Managing acute gastroenteritis among children, MMWR Recommendations Rep 53:1-33, 2004.

15. Kollaritsch $H$, Holst $H$, Grobara $P$, Wiedermann $G$. Prevention of travelers' diarrhea with Saccharomyces boulardii. Results of a placebo controlled double-blind study. Fortsschr Med1993;111:152-56.

16. Bleichner G, Blehaut $H$, Mentec $H$, Moyse $D$. Saccharomyces boulardii prevents diarrhea in critically ill tube-fed patients. Inten Care Med 1997;23:517-23. 
17. Saint-Marc T, Blehaut H, Musial C, Touraine JL. AIDSrelated diarrhea: a double blind trial of Saccharomyces boulardii. Sem Hop1995;71:735-41.

18. Kurugol Z, Koturoglu G. Effects of Saccharomyces boulardii in children with acute diarrhoea. ActaPaediatr2005;94:44-7.

19. Billoo AG, Memon MA, Khaskheli SA, Murtaza G, Iqbal K, SaeedShekhani M, Siddiqi AQ. Role of a probiotic (Saccharomyces boulardii) in management and prevention of diarrhoea. World $\mathrm{J}$ Gastroentero/2006;12:4557-560.

20. Villarruel G, Rubio DM, Lopez F, Cintioni J, Gurevech R, Romero G, Vandenplas Y. Saccharomyces boulardii in acute childhood diarrhoea: a randomized, placebocontrolled study. ActaPaediatr2007;96:538-41.

21. Gareau MG, Sherman PM, Walker WA. Probiotics and the gut microbiota in intestinal health and disease. Nat Rev GastroenterolHepatol2010;7:503-14.

22. Szajewska H., Horvath A., Piwowarczyk A. Metaanalysis: the effects of Saccharomyces boulardii supplementation on Helicobacter pylori eradication rates and side effects during treatment. Aliment PharmacolTher2010;32:1069-79.

23. Czerucka D, Piche T, Rampal P. Review article: yeast as probiotics-Saccharomyces boulardii. Aliment PharmacolTher 2007;26:767-78.

24. Pothoulakis C. Review article: anti-inflammatory mechanisms of action of Saccharomyces boulardii. Aliment PharmacolTher 2009;30:826-33

25. Czerucka D, Dahan S, Mograbi B, Rossi B, Rampal $P$. Saccharomyces boulardii preserves the barrier function and modulates the signal transduction pathway induced in enteropathogenicEscherichia coliinfected T84 cells. Infect Immun 2000;68:5998-6004.

26. Szajewska H, Setty M, Mrukowicz J, Guandalini S. Probiotics in gastrointestinal diseases in children: hard and not-so-hard evidence of efficacy. $J$ PediatrGastroenterolNutr2006;42:454-75.

27. Szajewska H., Skorka A. (2009) Saccharomyces boulardii for treating acute gastroenteritis in children: updated meta-analysis of randomized controlled trials. Aliment PharmacolTher2009;30:960-61.

28. McFarland L.V. (2010) Systematic review and metaanalysis of Saccharomyces boulardii in adult patients. World J Gastroenterol 16: 2202-2222 [PMC free article] [PubMed]

29. Bartlett J.G. (2002) Clinical practice. Antibioticassociated diarrhea. $N$ Engl $J$ Med 346: 334-339 [PubMed],

30. McFarland L.V. (2006) Meta-analysis of probiotics for the prevention of antibiotic associated diarrhea and the treatment of Clostridium difficile disease. Am J Gastroenterol 101: 812-822 [PubMed] /
31. Mansour-Ghanaei F., Dehbashi N., Yazdanparast K., Shafaghi A. (2003) Efficacy of Saccharomyces boulardii with antibiotics in acute amoebiasis. World J Gastroenterol 9: 1832-1833 [PMC free article] [PubMed]/

32. Gaon D., Garcia H., Winter L. (2003) Effect of Lactobacillus strains and Saccharomyces boulardii on persistent diarrhea in children.Medicina (B Aires) 63: 293-298 [PubMed]/

33. McFarland L.V. (2007) Meta-analysis of probiotics for the prevention of traveler's diarrhea. Travel Med Infect Dis 5: 97-105 [PubMed]

34. Tong J.L., Ran Z.H., Shen J., Zhang C.X., Xiao S.D. (2007) Meta-analysis: the effect of supplementation with probiotics on eradication rates and adverse events during Helicobacter pylori eradication therapy. Aliment PharmacolTher 25: 155-168 [PubMed]

35. Cain A.M., Karpa K.D. (2011) Clinical utility of probiotics in inflammatory bowel disease. AlternTher Health Med 17: 72-79 [PubMed]

36. Parkes G.C., Brostoff J., Whelan K., Sanderson J.D. (2008) Gastrointestinalmicrobiota in irritable bowel syndrome: their role in its pathogenesis and treatment. Am J Gastroenterol 103: 1557-1567 [PubMed]

37. Dinleyici E.C., Eren M., Yargic Z.A., Dogan N., Vandenplas Y. (2009) Clinical efficacy of Saccharomyces boulardii and metronidazole compared with metronidazole alone in children with acute bloody diarrhea caused by amebiasis: a prospective, randomized, open label study. Am J Trop Med Hyg 80: 953-955 [PubMed]

38. Elmer G.W., Moyer K.A., Vega R., Surawicz C.M., Collier A.C., Hooton T.M., et al. (1995) Evaluation of Saccharomyces boulardii for patients with HIV-related chronic diarrhoea and in healthy volunteers receiving antifungals. MicrobTher 25: 23-31

39. Buts JP; Bernasconi P; Vaerman JP; Dive C (1990). "Stimulation of secretory IgA and secretory component of immunoglobulins in small intestine of rats treated with Saccharomyces boulardii”. Dig. Dis. Sci. 35 (2): 251-6. doi:10.1007/BF01536771. PMID 2302983.

40. Buts JP; Bernasconi P; Van Craynest MP; Maldague P; De Meyer R (1986). "Response of human and rat small intestinal mucosa todoi: $10.1080 / 003655200750024326$. PMID 10720113.oral administration of Saccharomyces boulardii". Pediatr. Res.20 (2): 192-6. doi:10.1203/00006450-198602000-00020. PMID 3080730.

41. Keya Lahiri,Kapil Jadhavet al 2015 ,Bacillus Clausii As An Adjuvant Therapy In Acute Childhood Diarrhoea,IOSR Journal of Dental and Medical Sciences (IOSR-JDMS) e-ISSN: 2279-0853, p-ISSN: 2279-0861. Volume 14, Issue 5 Ver. I (May. 2015), PP 74-76 www.iosrjournals.org 